\title{
Passive and active behavioural contributions to patchiness and spatial pattern during the early life history of marine fishes
}

\author{
Ian R. Bradbury ${ }^{1,4, *}$, Paul V. R. Snelgrove ${ }^{1,2}$, Pierre Pepin $^{3}$ \\ ${ }^{1}$ Biology Department, and ${ }^{2}$ Canada Research Chair in Boreal and Cold Ocean Systems, Ocean Sciences Centre, Memorial \\ University of Newfoundland, St. John's, Newfoundland A1C 5S7, Canada \\ ${ }^{3}$ Department of Fisheries and Oceans, Memorial University of Newfoundland, St. John's, Newfoundland A1C 5X1, Canada
}

${ }^{4}$ Present address: Department of Biology, Dalhousie University, Halifax, Nova Scotia B3H 4H6, Canada

\begin{abstract}
Multiple ichthyoplankton surveys of Placentia Bay, Newfoundland during the spring and summers of 1997 and 1998 indicated that both passive and active processes contribute to spatial pattern in pelagic eggs and larval fish. Distribution patterns of pelagic eggs and early larvae in coastal Newfoundland waters were consistent with passive drift during development, but older larvae were associated with areas of high production. Recently hatched larvae from pelagic spawners decreased in size throughout the spawning season, reflecting seasonal decreases in egg diameter. Larvae from demersal eggs increased in size over the same time period, possibly reflecting retention and growth. Lloyd's index of patchiness calculated for pelagic eggs generally increased during development, suggesting passive retention. Patchiness decreased after hatch, then increased at approximately $10 \mathrm{~mm}$. We hypothesize that the observed spatial patterns in older larvae, seasonal size increases in larvae from demersal eggs, and ontogenetic changes in patchiness reflect active processes. Predator patchiness, ontogenetic changes in spatial patterns, and published larval consumption rates support the hypothesis that mortality did not generate this pattern. Furthermore, mean crowding of capelin larvae by potential prey increased with development. Increases in patchiness during late larval development coincided with the size at which swimming ability was predicted to exceed ambient flow. This pattern suggests that larger larvae may actively contribute to their spatial distribution. We conclude that swimming ability and behaviour become increasingly important in determining spatial distribution patterns as pelagic larvae develop.
\end{abstract}

KEY WORDS: Ichthyoplankton · Swimming $\cdot$ Patchiness $\cdot$ Advection $\cdot$ Larvae

Resale or republication not permitted without written consent of the publisher

\section{INTRODUCTION}

The distribution of animals in space and time is seldom random and often patchy in nature (Lloyd 1967). The search for an understanding of the causes of spatial and temporal patterns in marine animals has long been at the forefront of marine ecology (e.g. MacCall 1990). The majority of marine organisms possess a pelagic phase, and distribution during this stage is believed to be a complex interaction of hydrography (e.g. Pepin et al. 1995) and behaviour (e.g. Butman et al. 1988). In turn, the realized spatial and temporal pat- tern during this period may play an important role in regulating survivorship, recruitment, and population stability (Gaines \& Bertness 1992, Roughgarden et al. 1988, Sinclair 1988). Notwithstanding the recognition that larval behaviour may influence spatial pattern and population structure at small (e.g. $\mathrm{cm}$ to $\mathrm{m}$ ) spatial scales, its role at larger scales and in setting broad patterns has been difficult to document, and thus remains relatively untested (Bradbury \& Snelgrove 2001).

Evidence in support of local recruitment in marine systems has begun to accumulate (Jones et al. 1999, Swearer et al. 1999, Thorrold et al. 2001), and explana- 
tions for observed recruitment patterns increasingly invoke larval behaviour as a key factor (e.g. Cowen et al. 2000). Laboratory studies suggest that swim speeds of marine fish larvae may increase dramatically during development (Williams et al. 1996) and direct observations of swimming and sensory capabilities of late stage reef fish larvae (e.g. Leis \& Carson-Ewart 1999) indicate surprisingly advanced larval abilities. The evolution of swimming capacity should contribute to pattern through directed horizontal movement (e.g. Hare et al. 2001) or through vertical migration in sheared flows (e.g. Fortier \& Leggett 1982, Grioche et al. 1999).

Historically, the delineation of active contributions to spatial pattern has proved problematic partly because of a lack of understanding of passive processes. More recently, an understanding of the physical dynamics of larval transport (e.g. Werner et al. 1999) has outpaced advances in the understanding of behavioural processes, notwithstanding recent advances in evaluation of larval swimming capacity. The implications of this dichotomy are far-reaching because underestimating larval ability and its consequences for dispersal and recruitment could be directly linked to our inability to predict the connectivity between habitats and to effectively manage marine fish populations (e.g. Warner et al. 2000, Mora \& Sale 2002).

The goal of this study was to examine the relative contributions of advection and active processes to observed spatial patterns in pelagic eggs and larvae, and to relate these contributions to life history strategies and larval development. Specifically, we hypothesized that larvae will reach a critical size at which active contributions override advection as the dominant factor in determining spatial pattern. We also hypothesized that the relative roles of active and passive processes are constrained by the life history strategies of fishes, in that higher active contributions are expected in species with demersal eggs, larger larvae, and schooling adults.

\section{MATERIALS AND METHODS}

Field sampling. The majority of the analyses reported herein are based on data collected from Placentia Bay, Newfoundland, Canada, where a grid of 45 stations was sampled during the day between 07:00 and 19:00 $\mathrm{h}$ through the spring and summer in 1997 and 1998 (Fig. 1). At each station a $4 \mathrm{~m}^{2}$ Tucker trawl (mesh sizes $1 \mathrm{~mm}, 570 \mu \mathrm{m}$, and $333 \mu \mathrm{m}$ ) was deployed at $\sim 2$ knots over double oblique tows to $40 \mathrm{~m}$. The resulting data were used to characterize ichthyoplankton and zooplankton distributions. Conductivitytemperature-depth data obtained with a Seabird 19 or
Seabird 25 were paired with each tow. This pairing facilitated the mapping of temperature and stratification over space and time. Additional details of the collection and identification methodologies are reported in Bradbury et al. (2000). Briefly, ichthyoplankton were sorted to species or to the lowest taxonomic level possible. All eggs were staged following the protocol of Markle \& Frost (1985). Egg abundance estimates were corrected for the number of eggs that could not be staged due to damage $(<5 \%)$.

The abundance of juvenile and adult capelin in Trinity Bay was estimated from an acoustic survey that employed a calibrated hull-mounted split-beam $38 \mathrm{kHz}$ transducer and an EK500 echosounder system. Capelin were distinguished from other fish backscatter using echogram characteristics combined with fishing sets. The methodologies used for estimating abundance are presented in O'Driscoll et al. (2000). Given the similar ecology, species composition, and geographic proximity of Trinity and Placentia Bays, and the fact that patchiness in adult capelin is likely in response to environment and other factors rather than a direct product of any local environmental differences, we believe that the use of the capelin patchiness data from Trinity Bay as a proxy for such patterns in Placentia Bay is justified.

All catch data were ordered by larval size and stage; abundances expressed as contour plots were normalized to volume, using data from flow meters mounted in the mouth of the Tucker trawl (see Bradbury et al. 2000). In our patchiness analyses, we did not convert abundances to concentrations because of problems created by standardizing (Bez 2000, and see next subsection). The examination of spatial pattern was based on contoured abundance plots generated using Surfer 7 for Windows 98 and a linear kriging approach. Spatial analysis of associations between mean propagule size and environmental variables were examined using Pearson correlations with Bonferroni-adjusted $\mathrm{p}$-values. Seasonal changes in the egg and larval size of dominant taxa were examined using a $G$-test of independence (Sokal \& Rohlf 1995).

Patchiness analysis. Lloyd's index of patchiness $\left(P_{;}\right.$ Lloyd 1967) has been used extensively to study patchiness in ichthyoplankton (Hewitt 1981, Stabeno et al. 1996) and more recently in settled juveniles (Methven et al. 2003). Its attractiveness rests in its logical interpretation (i.e. how many times more crowded the average individual in a given distribution is relative to an individual drawn from a population having the same mean density, but which is randomly distributed). It is also independent of density and the scale of sampling. Lloyd's index is defined as:

$$
P=1+\frac{\left(\sigma^{2}-\bar{\chi}\right)}{\bar{\chi}^{2}}
$$


where $\bar{\chi}$ is the population mean and $\sigma^{2}$ is the population variance. Unfortunately, the substitution of the sample estimates into Eq. (1) provides an estimate of $P$ for which the standard error cannot be reliably estimated (Bliss \& Fisher 1953). Estimating the standard error requires assumptions regarding the underlying distribution (Lloyd 1967). Following the example of previous authors (Hewitt 1981, Matsuura \& Hewitt 1995, Stabeno et al. 1996) we fitted a negative binomial to the ichthyoplankton catch data. The negative binomial is described as:

$$
(p-q)^{-\kappa}
$$

where $p=m / \kappa, q=1+p$ ( $p$ and $q$ are the expected proportions in 2 contrasting categories), $m$ is the mean of the negative binomial distribution and $\kappa$ is a dispersion parameter. The value for $m$ is easily estimated from the sample data; however, $\mathrm{k}$ must be solved by iteration using a maximum likelihood expression (Bliss \& Fisher 1953):

$$
N \log _{\mathrm{e}}\left[1+\left(\frac{\operatorname{mean}\left(X_{i}\right)}{\kappa}\right)\right]=\sum\left[\frac{f\left(X_{i}\right)}{\kappa+\left(X_{i}\right)}\right]
$$

where $N$ is the number of samples, and $f\left(X_{\mathrm{i}}\right)$ is the frequency of all samples containing $X$ individuals (Bliss \& Fisher 1953). An iterative solution was found by employing the equation solver in Excel 2000. However, given the limitations of this solver (such as the tendency towards local minima), we examined the effi-

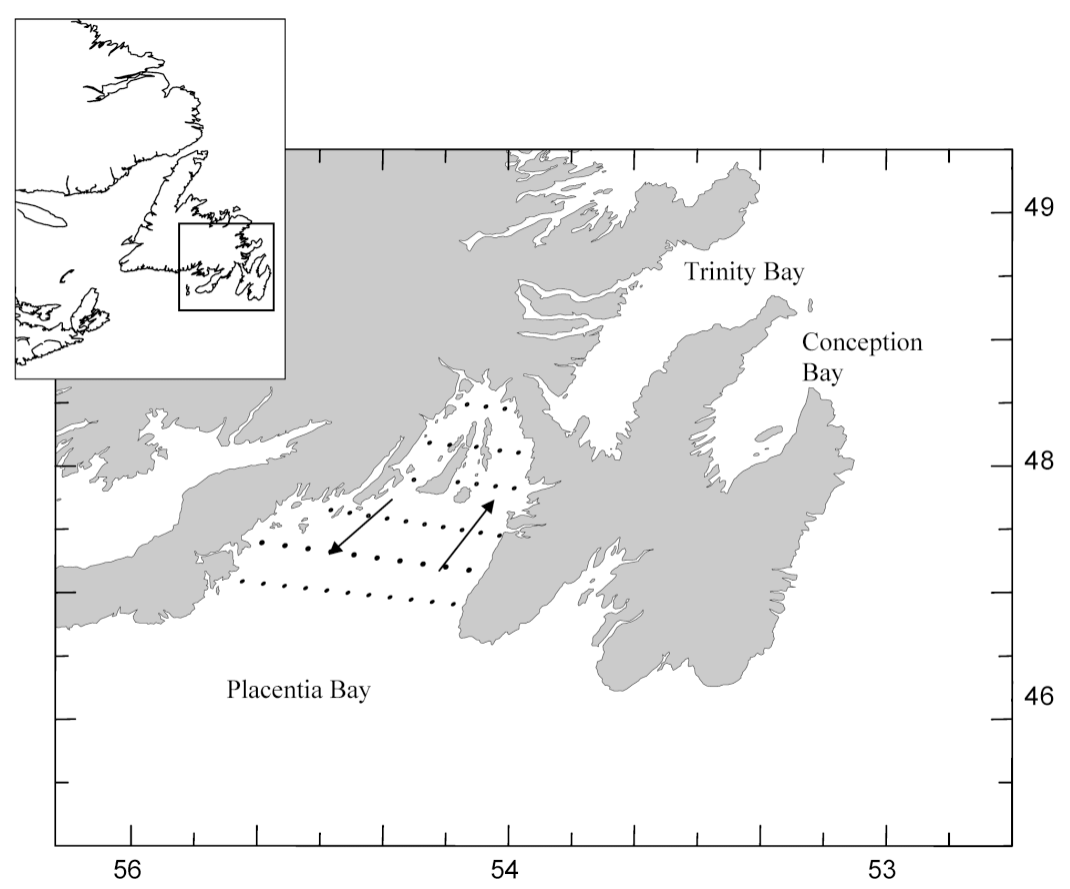

Fig. 1. Map of eastern Newfoundland, closed circles indicate sampling stations in Placentia Bay; inset shows position in relation to Newfoundland. Arrows indicate mean horizontal circulation from Bradbury et al. $(2000,2001)$ cacy of this technique using the frequency data and estimates of $\kappa$ from Matsuura \& Hewitt (1995). The 2 approaches were $99 \%$ consistent. $P$ could then be calculated from its relationship to $\kappa$ :

$$
P=1+1 / \kappa
$$

The standard error (SE) was then estimated using the expression:

$$
\mathrm{SE}(P)=\frac{1}{\hat{\kappa}^{2} \sqrt{\operatorname{var}(\hat{\kappa})}}
$$

where $\hat{\kappa}$ is the estimate of $\kappa$ based on an observed frequency distribution and $\operatorname{var}(\hat{\kappa})$ is the sampling variance of $\kappa$ (see Bliss \& Fisher 1953). This method requires large sample sizes, and therefore we estimated SE only for the species whose eggs and larvae were abundant in the samples. This sample size restriction made it necessary to combine catch data for all cruises in order to achieve sufficient numbers for comparisons. Even then we were unable to compute patchiness for some size bins of even the most common species.

Samples lacking larvae of any size are problematic because these stations may be located outside the species' range or they may represent real patchiness within the range. For this reason, many authors have included only those stations at which at least one individual was caught in the analysis (Hewitt 1981, Matsuura \& Hewitt 1995, Methven et al. 2003). McGurk (1986) investigated the effect of including zero stations and found that patchiness increased by the ratio of the count of zero stations to total samples. We evaluated this effect and found that including zero stations increased patchiness by an average of $55 \%$. Nonetheless, the overall patterns that emerged were similar regardless of whether zero stations were included or excluded (Pearson correlation coefficient of 0.92 ). We included zero stations because the area sampled was well within the known geographic range of the species examined (e.g. McGurk 1986, Stabeno et al. 1996).

Capelin larvae were abundant in a wide range of sizes (i.e. development) and displayed a clear transition in spatial pattern during development. Capelin larvae were also the dominant taxon during the summer months when production was most spatially structured. These attributes made it the preferred model with which to explore influences of prey and predator patchiness on larval patchiness. Patchiness values for predator species were calculated as stated above using abundances of the various predator classes. In this analy- 
sis we grouped predators into gelatinous zooplankton, crustaceans or fish. The former 2 categories were based on catches in the Placentia Bay plankton tows. Fish patchiness indices were derived from the acoustic surveys of adult capelin conducted in Trinity Bay. Because larval aggregation may be in response to prey availability, we calculated the quantity of food available per individual using Lloyd's index of mean crowding (Lloyd 1967). The mean crowding of prey on capelin larvae (capelin) was estimated using the equation:

$$
\dot{\boldsymbol{X}}_{\text {prey(capelin) }}=\frac{\sum_{j=i}^{q} \boldsymbol{X}_{\text {prey } \cdot j} \boldsymbol{X}_{\text {capelin } \cdot j}}{\sum_{j=i}^{q} \boldsymbol{X}_{\text {prey } j}}
$$

where $\dot{x}_{\text {prey(capelin) }}$ is the estimate of mean crowding of prey species on capelin larvae and $x_{\text {prey } \cdot j}$ and $x_{\text {capelin } \cdot j}$ are the numbers of prey and capelin larvae at the $j$ th station. In this analysis, total potential prey was calculated by combining all 1 to 3 copepodite stages of all species into a single category.

\section{RESULTS}

\section{Spatial changes during development}

Three species with pelagic eggs, American plaice, Atlantic cod, and cunner, were caught in sufficient numbers to contour (Fig. 2). The spatial distribution of egg stages exhibits a southwest progression with development, which is consistent with drift. The smallest size classes of larvae in these taxa were associated with the western boundary of the bay, where late stage eggs were also most abundant. Larger size classes occurred progressively toward the southeast. This too is consistent with drift. Early-stage eggs of all species were associated with the head of the bay and its western side. Patterns of later stages in plaice and cod were consistent with southwest transport toward the mouth of the bay. This pattern of movement with development was not observed in cunner eggs. Cunner eggs were consistently associated with areas near islands in the head of the bay and along its western side.

The patterns of larval distributions were similar to those observed for eggs (Fig. 3). Early-stage larvae of 3 of the 4 most common species (cod, cunner, capelin) were associated consistently with islands in the head of the bay or along the western side. Sandlance abundances were highest for all size classes in the central portion of the bay. The smallest larvae of cod and cunner were consistently concentrated near the outer western side of the bay. As these species developed, their peak concentrations shifted towards the head of the bay (Fig. 3), where areas of high production were observed (Bradbury et al. 2000). Small capelin larvae were most abundant near the islands in the center of the bay, but their abundance shifted to the outer western side with increased size. The western side of the bay is characterized by higher levels of upwelling and zooplankton production in August (P. V. R. Snelgrove unpubl. data). Distribution patterns of sandlance larvae were similar across size groups and were concentrated in the outer bay. We examined the larval size distribution for all species in relation to environmental variables using Pearson correlation coefficients. Some significant correlations occurred, but the patterns were inconsistent and correlations often exhibited reversed signs in different months.

\section{Temporal changes during development}

Mean pelagic egg size for the 2 species (Atlantic cod and American plaice) with comprehensive temporal coverage exhibited significant seasonal decreases with increasing temperature (Fig. 4A for American plaice, Fig. 4B Atlantic cod). Temporal trends in size were apparent in larval cod, which was the only species for which pelagic eggs and larvae were consistently sampled. Mean larval size decreased throughout the sampling period from April to October (Fig. 4C). In contrast, the mean larval size for sandlance (the only taxon hatched from demersal eggs that was consistently present in multiple months) increased throughout the sampling period from April to June (Fig. 5). Size frequencies were compared between sequential months and were all significantly different (Table 1), with the exception of the comparison between May and June 1997. For several other species with demersal eggs that were sampled on consecutive cruises, similar increases were observed. For example, between April and June 1997, Myoxocephalus scorpius increased from a mean length of 7.8 to $10.6 \mathrm{~mm}$ ( $\mathrm{p}<0.0005$, df $=81$ ) and Liparis sp. increased from a mean of 11.6 to $13.5 \mathrm{~mm}$ $(\mathrm{p}<0.0005, \mathrm{df}=66)$.

Table 1. Ammodytes sp. Comparison of sandlance frequency distributions sampled in the spring and summer of 1997 and 1998 using a row-by-column contingency test

\begin{tabular}{|lccc|}
\hline Comparison & df & G-statistic & p-value \\
\hline April-May 1997 & 34 & 227.76 & $<0.005$ \\
May-June 1997 & 33 & 36.67 & $0.9>\mathrm{p}>0.1$ \\
April-June 1997 & 35 & 61.90 & $<0.025$ \\
April-June 1998 & 26 & 60.92 & $<0.005$ \\
\hline
\end{tabular}




\section{Patchiness}

Patchiness generally increased during development for all 3 species with pelagic eggs (Atlantic cod, American plaice, cunner; see Fig. 6A,C). Patchiness esti- mates were much higher for cunner than for either cod or plaice (not shown). Larval patchiness was initially high at hatch, decreased strongly post-hatch, and subsequently rose sharply. This produced a U-shaped function. The absolute value and range of patchiness
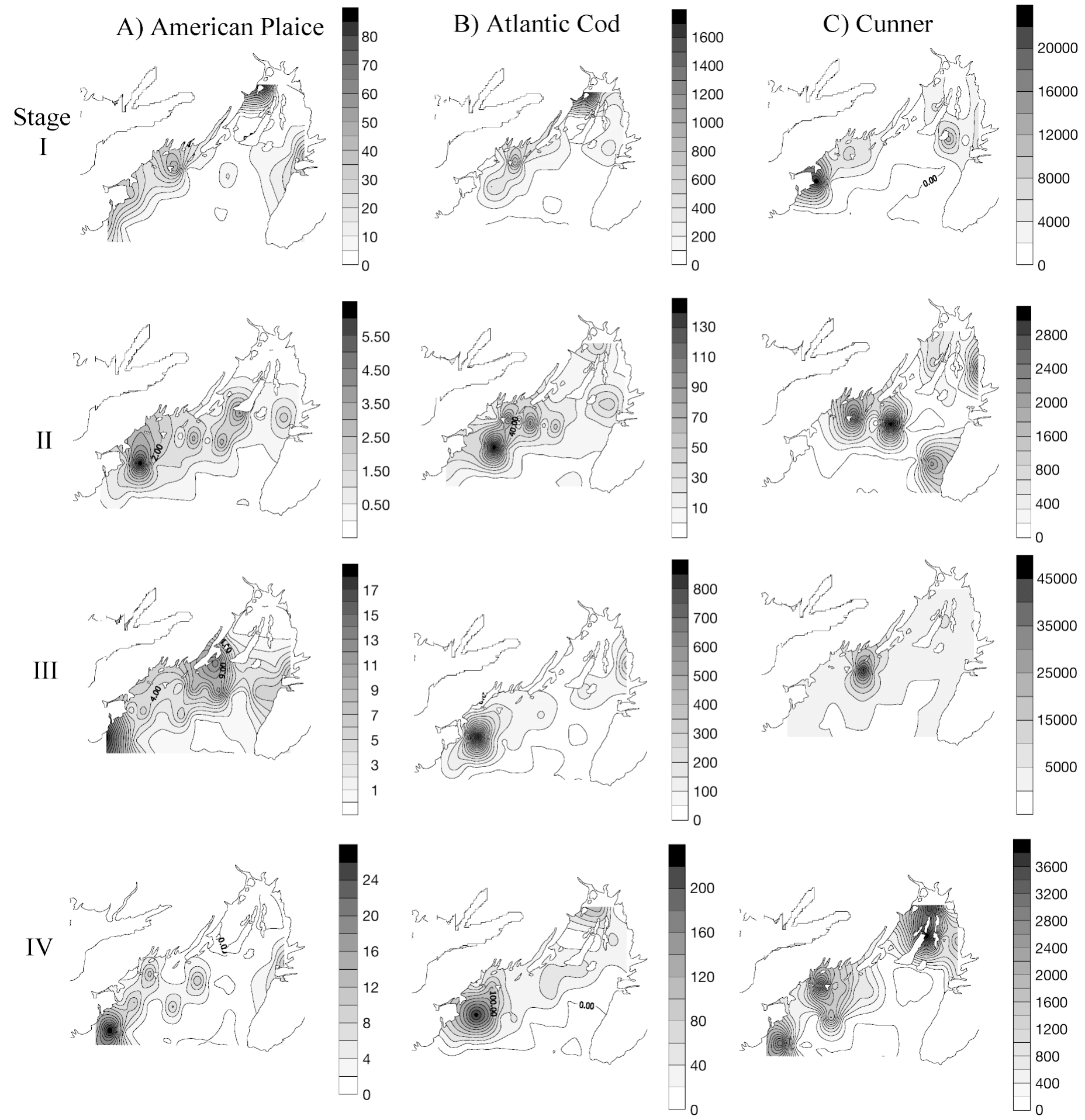

Fig. 2. Distribution of eggs of (A) American plaice Hippoglossoides platessoides, (B) Atlantic cod Gadus morhua and (C) cunner Tautogolabrus adspersus (\# per tow) sampled throughout Placentia Bay in August 1998. Eggs divided into developmental stages based on Markle \& Frost (1985) 
A) Atlantic Cod

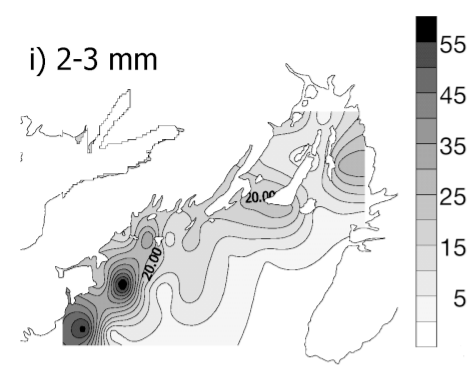

ii) $4-5 \mathrm{~mm}$

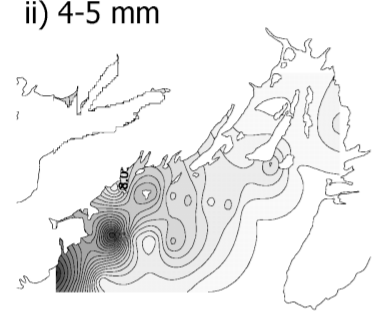

iii) 6-7 mm

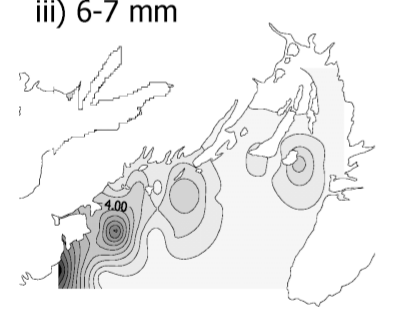

iv) $8-9 \mathrm{~mm}$
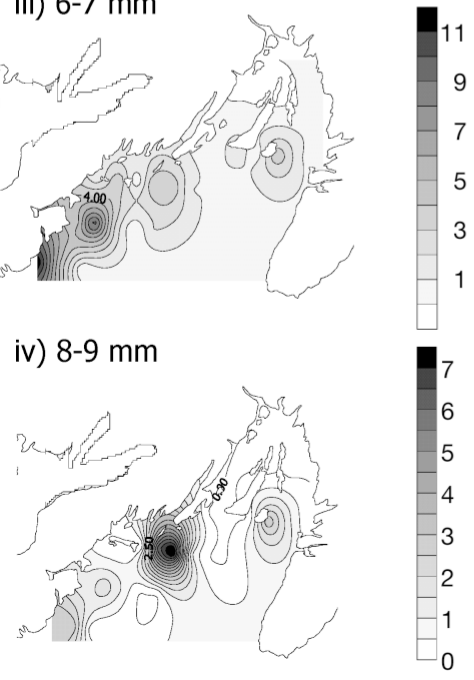

B) Cunner
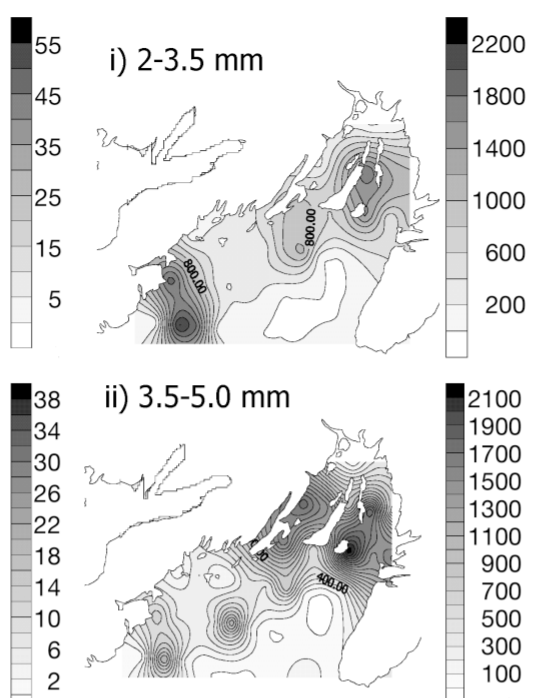

iii) 5-6.5 mm

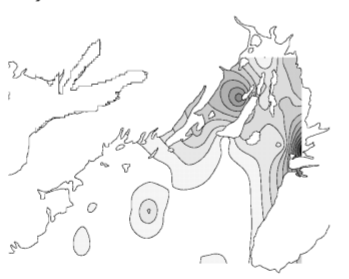

iv) $6.5-8.0 \mathrm{~mm}$

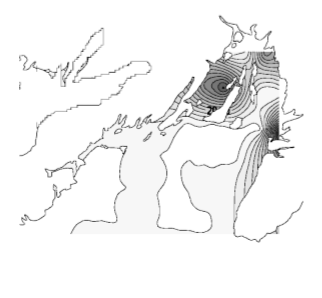

C) Capelin

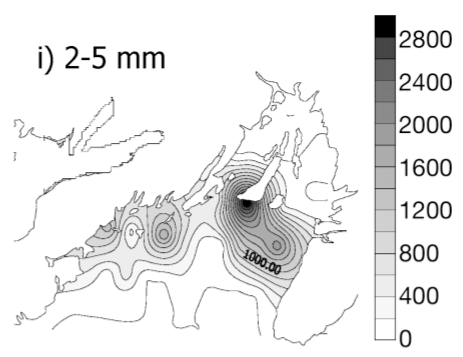

ii) $5.0-8.0 \mathrm{~mm}$

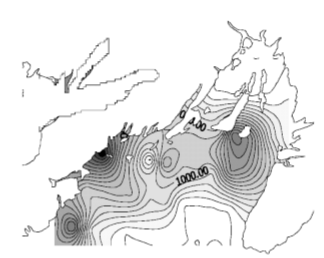

iii) $8.0-11.0 \mathrm{~mm}$

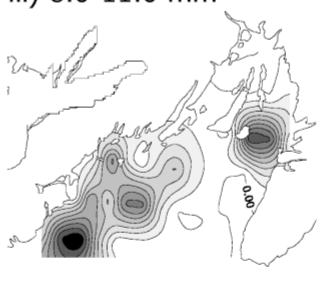

iv) $11.0-14.0 \mathrm{~mm}$

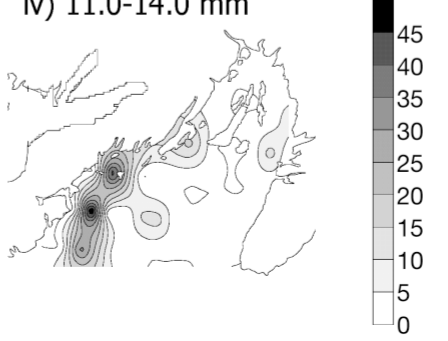

D) Sandlance

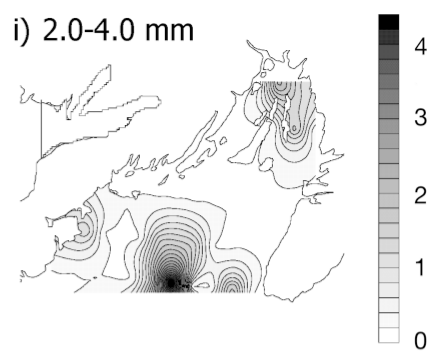

ii) $4.0-6.0 \mathrm{~mm}$

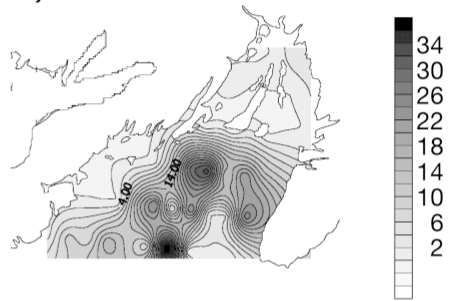

iii) $6.0-8.0 \mathrm{~mm}$

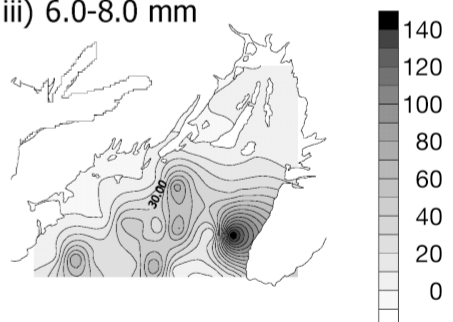

iv) $8.0-10.0 \mathrm{~mm}$

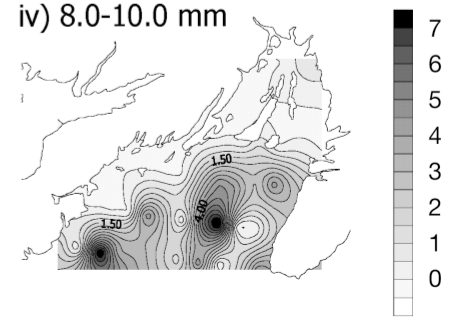

Fig. 3. Distribution of larvae of (A) Atlantic cod Gadus morhua, (B) cunner Tautogolabrus adspersus, (C) capelin Mallotus villosus and (D) sandlance Ammodytes sp. (\# per tow) sampled throughout Placentia Bay in August 1998, with the exception of sandlance (sampled in June 1998)

estimates during development were highest for pelagic schooling species with demersal eggs (capelin, sandlance). Cod larvae, the least abundant of the 4 species, had the highest standard error and least defined curve. Because plaice larvae were rare, patchiness estimates could not be calculated and data are not shown. The patchiness estimates of coincident predator groups were consistently low, and were consistent with the minimal values observed for larvae (Fig. 7A). In contrast, larval size of capelin generally increased with the quantity of food available per individual, as expressed by the mean crowding index (Fig. 7B), though the linear regression was not significant.

\section{DISCUSSION}

Wild animal populations are characteristically patchy and non-randomly distributed (Lloyd 1967); this is particularly true of marine fishes (e.g. Hewitt 1981, Methven et al. 2003). We examined the nature and magnitude of passive and active behavioural factors operating during the egg and larval stages of several abundant marine species in relation to larval patchiness in coastal Newfoundland, a spatially and temporally variable environment. We built on previous studies that have examined patterns of egg development and species composition in this environment. These studies have shown that passive processes regulate the 
development of spatial and temporal patterns during the egg and early larval period (Bradbury et al. 2000, 2001, P. V. R. Snelgrove unpubl. data). In this study we focused on larval size and egg and larval patchiness in an effort to evaluate the hypothesis that active behav-
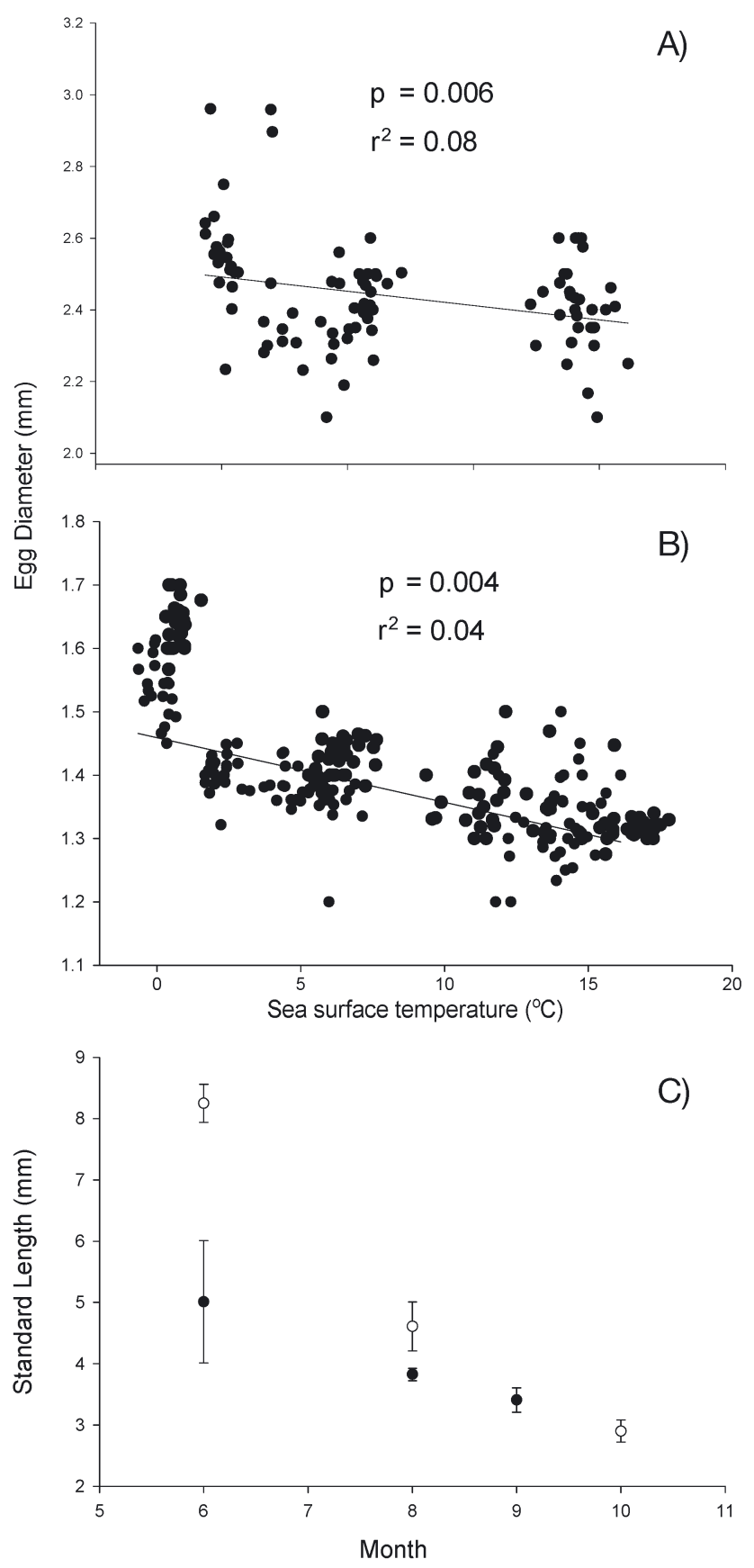

Fig. 4. Temporal changes in egg diameter of (A) American plaice Hippoglossoides platessoides and (B) Atlantic cod Gadus morhua, and (C) mean larval size for Atlantic cod sampled in Placentia Bay in 1997 (0) and 1998 (•). Note that plaice larvae were collected only in August, preventing any analysis of larval size and temperature ioural contributions to pattern are increasingly important as larval development progresses. The ability of fishes to influence their spatial distribution and dispersal during their early life history has important implications for habitat connectivity and population stability in the marine environment (e.g. Warner et al. 2000).

\section{Spatial pattern}

The changes in spatial distribution patterns during the egg and early larval period of fishes we studied clearly indicate the importance of advection. American plaice, Atlantic cod and cunner all exhibited a shift in spatial distribution with development during the egg stage that is consistent with passive transport out of the western side of Placentia Bay following spawning near the head of the Bay. Circulation data from Placentia Bay indicate strong and relatively consistent flows into the bay along the eastern side, weak and variable at its head, and southwesterly along the western side of the

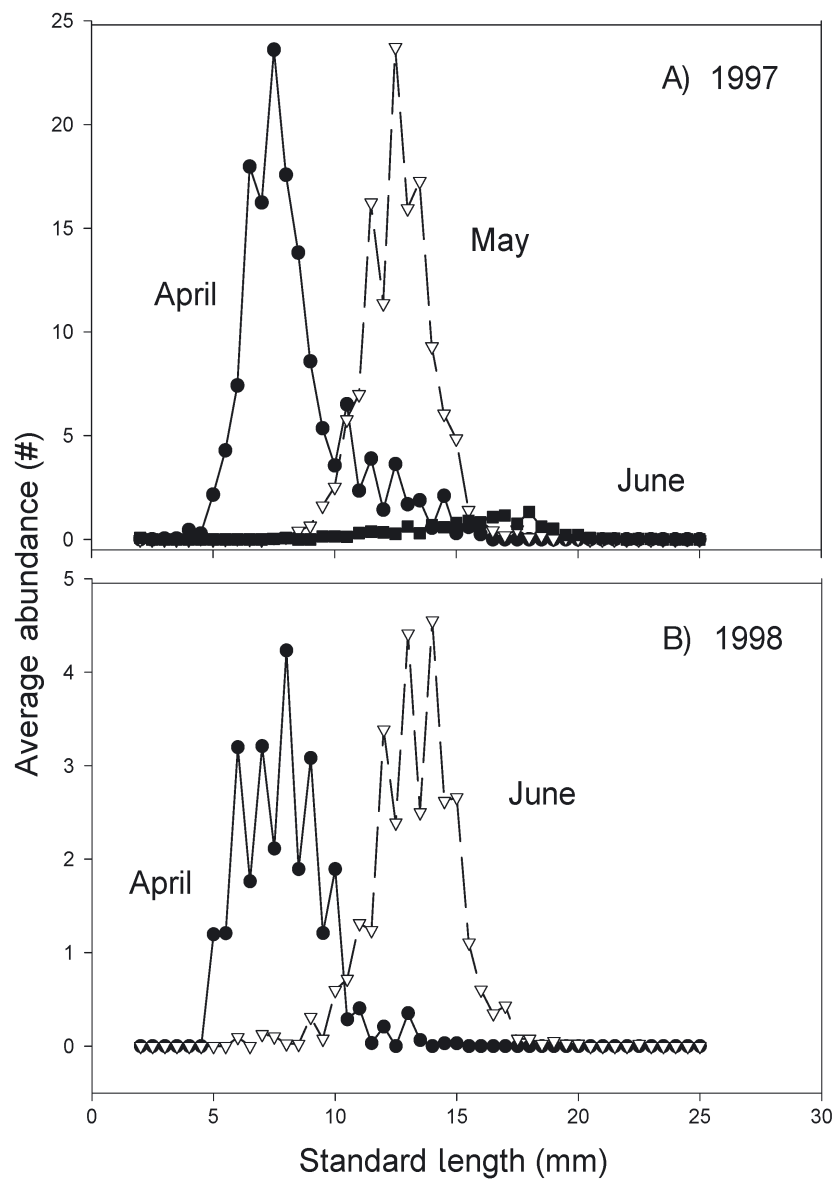

Fig. 5. Ammodytes sp. Temporal changes in the frequency distribution of sandlance larval length-frequency distributions sampled in (A) 1997 and (B) 1998 

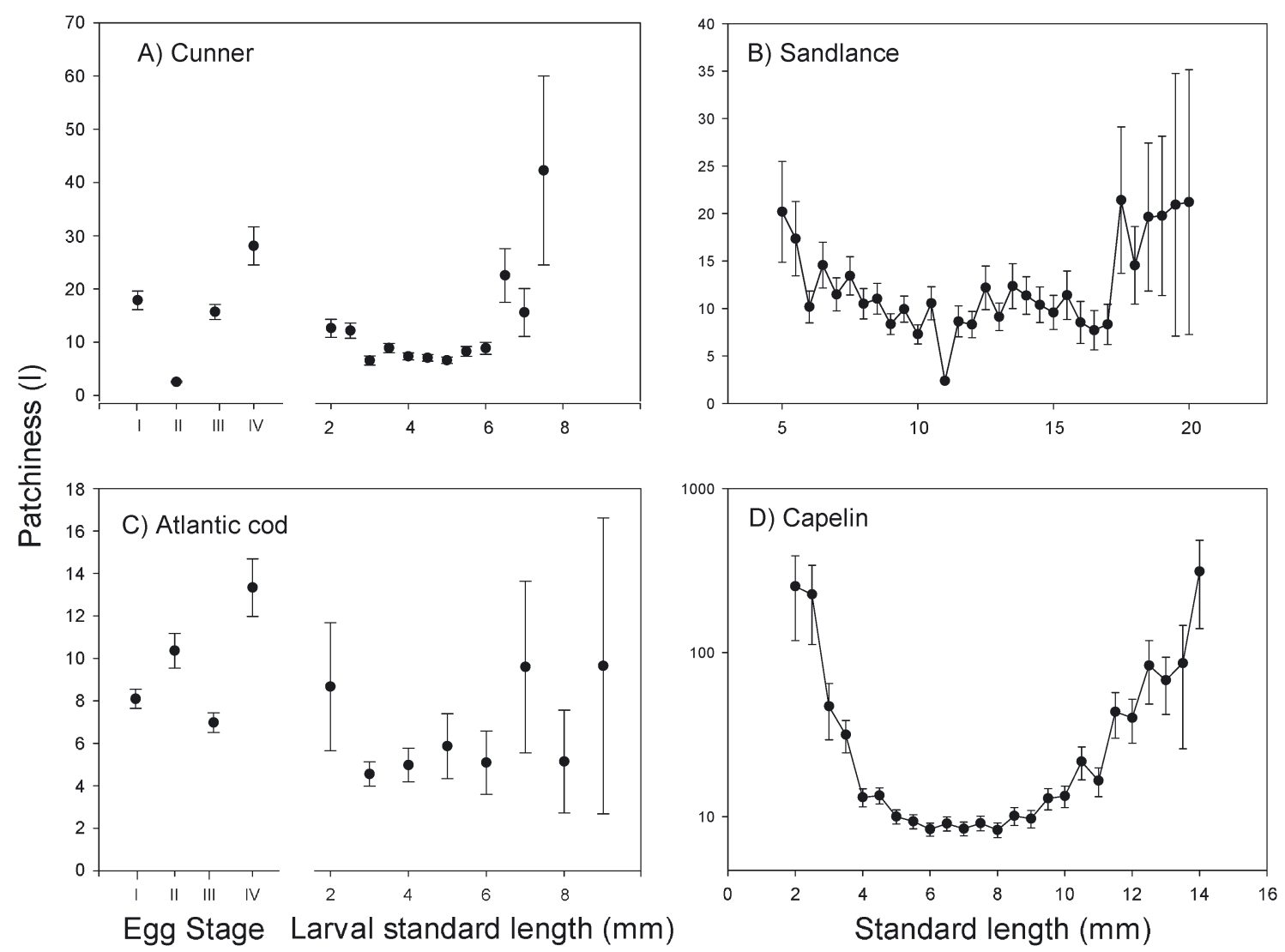

Fig. 6. Changes in Lloyd's index of patchiness ( $\pm 2 \mathrm{SE}$ ) with egg stage and larval size for (A) cunner Tautogolabrus adspersus, (B) sandlance Ammodytes sp., (C) Atlantic cod Gadus morhua and (D) capelin Mallotus villosus sampled in Placentia Bay. Patchiness estimates include all surveys during 1997 and 1998. See 'Materials and methods' for details

bay (Bradbury et al. 2000, Schillinger et al. 2000). Bradbury et al. $(2000,2001)$ have demonstrated that offshore advection may be a factor limiting Atlantic cod recruitment in Placentia Bay. P. V. R. Snelgrove (unpubl. data) have observed how spatial patterns exhibited in ichthyoplankton communities may reflect a tradeoff between the seasonal timing of spawning and spawning strategy, in that pelagic eggs are vulnerable to offshore transport when low water temperatures prolong egg development and larval hatch times. Nonetheless, declines in numbers of individuals could indicate either advective or predation loss. In this system we have previously argued that advection has the greatest effect (Bradbury et al. 2001).

If larval distributions are determined primarily by passive processes, increasingly larger larvae would be expected to dominate catches as larvae are transported to increasingly larger distances from the spawning sites along the bay's western side. In fact, a markedly different pattern was observed. Larger individuals of cod, capelin and cunner occurred 'upstream' of areas where smaller larvae and late stage eggs were most abundant. The most plausible explanation for this pat- tern is active swimming by larvae as they become larger and stronger swimmers (Williams et al. 1996), and these larger individuals are increasingly capable of regulating their distributions. From an adaptive perspective, such behaviour would cause larvae to move towards areas of the bay where food resources are, on average, most abundant. An alternative, but less likely explanation, is that differential predation or mortality selectively removes larvae of specific size classes, thereby producing the size distribution observed.

\section{Temporal pattern}

We have shown elsewhere that larvae hatched from demersal eggs are generally larger and better developed relative to those hatched from pelagic eggs (P. V. R. Snelgrove unpubl. data) and this conclusion is consistent with the work of other authors (e.g. Suthers \& Frank 1991). Such a pattern would cause larvae from demersal spawners to be less vulnerable to flushing from the bay, particularly in spring (P. V. R. Snelgrove unpubl. data), when cold temperatures would be 


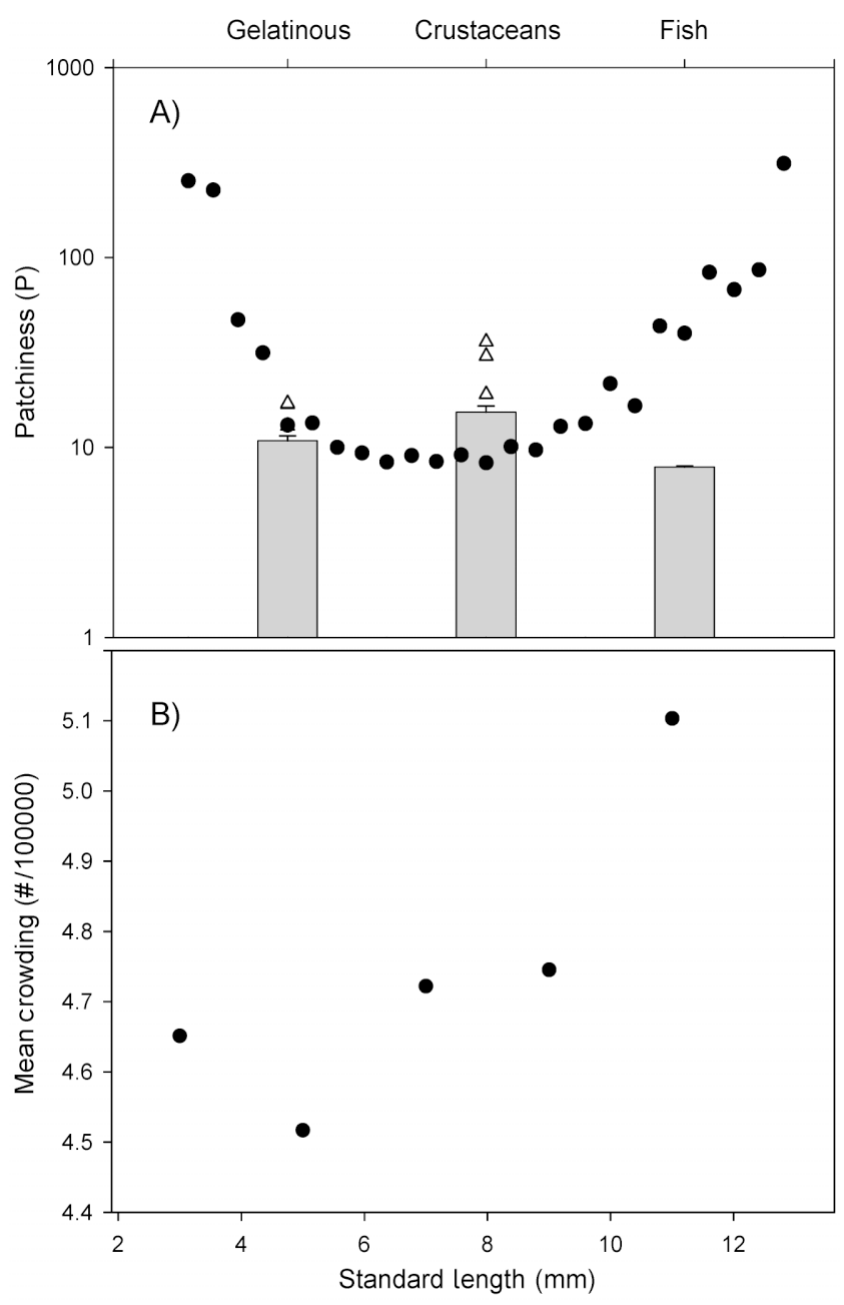

Fig. 7. (A) Changes in patchiness for capelin Mallotus villosus larvae (from Fig. 6) in relation to patchiness estimates for various predator groups, as indicated at the top of the panel ( $\triangle$ : individual species estimates). (B) Estimates of mean crowding of capelin larvae by potential prey with changes in larval size

expected to contribute to slower growth rates (Pepin 1991). This difference in size at hatch and swimming ability may also be reflected in spawning times. Typically, higher numbers of larvae from pelagic spawners occur in late summer, whereas larvae from demersal spawners predominate in spring and early summer (P. V. R. Snelgrove unpubl. data). In Atlantic cod, mean egg size and larval size both decrease from spring through summer. The decrease in egg size later in the spawning season is consistent with findings elsewhere, suggesting a relationship between egg size and water temperature (Chambers 1997). This reduction in egg size may produce the shift to smaller larvae later in the season because smaller eggs produce smaller larvae (Zhao et al. 2001). This reduction, in turn, may help limit the capacity of larvae to regulate their distributions.
Perhaps more important to the discussion here is the observation that larger cod larvae are relatively rare, even late in the season when total numbers of cod larvae are highest (Bradbury et al. 2000). This pattern is consistent with the explanation that most of the larvae from cod, and some other pelagic spawners, are flushed from Placentia Bay before they achieve sufficient sizes to allow them to counter the effects of current transport by swimming. By contrast, shifts in the size frequency distribution of larvae from demersal eggs such as sandlance show an increase in size from spring to summer, a pattern that is consistent with the retention of growing individuals. Although the size differences observed are suggestive of slow growth rates (Pepin et al. 1995), surface waters in Placentia Bay are relatively cold at the time of year when sandlance are most numerous, and slow growth rates would therefore be expected. The contrasting findings for cod and sandlance are consistent with the hypothesis that larvae from demersal spawners are more highly developed at hatch than those from demersal spawners (Thresher 1984), and are therefore capable of maintaining their association with the coastal environment (P. V. R. Snelgrove unpubl. data).

A simple scaling argument demonstrates the potential implications of size for swimming speed and, by extension, the capacity for active behavioural processes to contribute to the patterns observed (Fig. 8). Williams et al. (1996) report the evolution of larval burst swim speed capacity for several fish species

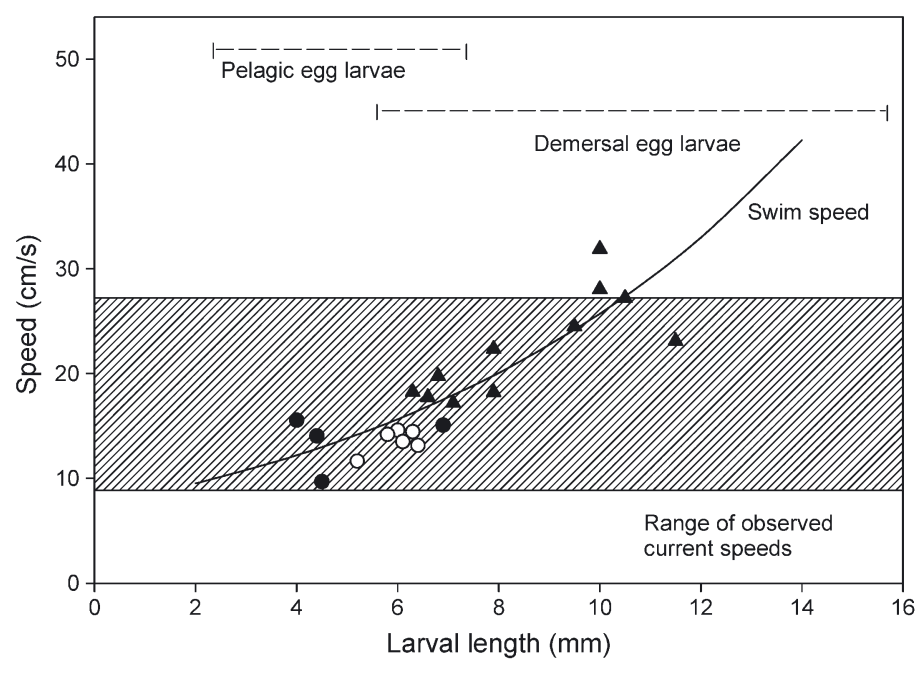

Fig. 8. Changes in maximum larval swim speed with larval size (solid line from Williams et al. 1996) compared with average hourly ambient flow conditions (hatched box) and size ranges (dashed lines) for pelagic and demersal-egg larvae from Placentia Bay, Newfoundland, during 1997 and 1998. Estimates of maximum swim speed for $(\bullet)$ Atlantic cod Gadus morhua, (O) capelin Mallotus villosus, and (ム) radiated shanny Ulvaria subifurcata; all data from Williams et al. (1996) 
during development, and these estimates may be used as a maximum or best-case scenario for active contributions. A comparison of swim speeds for larvae produced from pelagic eggs with those of larvae produced from demersal eggs allows the following conclusions to be drawn. First, larvae from demersal spawners are larger and therefore presumably faster swimmers than larvae from pelagic spawners, except at the upper size limit for pelagics. Second, when swim speeds are compared to average flows representative of Placentia Bay (Schillinger et al. 2000) and other Newfoundland embayments (e.g. Pepin et al. 1995), swim speeds of larvae hatched from demersal eggs are well within the ranges of typical ambient flow. The same can be said only for the most advanced and largest larvae from pelagic spawners. Pelagic spawning taxa are therefore more likely to be vulnerable to the displacement effects of advection.

From a larval perspective, horizontal diffusivity, rather than advection, may be more important in generating or maintaining spatial distribution. We therefore examined patch stability in relation to horizontal diffusivity. Following Stabeno et al. (1996), we used a steady-state approximation of an advection diffusion equation $\left(C_{(\mathrm{r})}=C_{0} \mathrm{e}^{-\mathrm{Ur} / \mathrm{K}_{\mathrm{H}}}\right.$, where $C_{(\mathrm{r})}$ is the concentration at the patch perimeter, $C_{0}$ is the concentration at the patch origin, and Ur and $\mathrm{K}_{\mathrm{H}}$ are larval swim speed and horizontal diffusivity respectively) to estimate the constant swim speed required to maintain patch structure. In contrast to Stabeno (1996), who estimated the horizontal diffusivity based on patch radius, we used measured diffusivity values from coastal Newfoundland. These range from 70 to $100 \mathrm{~m}^{2} \mathrm{~s}^{-1}$ (deYoung \& Sanderson 1995). We estimate that the swim speed required to maintain $99 \%$ of the patch sizes observed in Placentia Bay ranges between 1.0 and $1.2 \mathrm{~cm} \mathrm{~s}^{-1}$. Sustained larval swim speeds typically range between 1 and 2 body lengths per second (Bradbury \& Snelgrove 2001), and larvae $10 \mathrm{~mm}$ or greater in length should be capable of contributing substantially to their spatial distribution. This outcome corresponds with our previous estimate based on burst speeds and advection rates, and further supports the argument that active processes may begin to play a greater role as larvae attain a critical size.

The assumption inherent in the above discussion is that larvae are capable of directed movement, which requires a frame of reference or a landmark from which to navigate. Recent work is improving our understanding of larval sensory abilities and supports the hypothesis that this sort of directional swimming facilitated by surprising advanced sensory abilities is possible (Kingsford et al. 2002). In fact, directed larval swimming has been observed in relation to reefs up to $10 \mathrm{~s}$ of $\mathrm{km}$ away (Leis \& Carson-Ewart 1999). The capacity for directed swimming is a major assumption; however, there is increasing evidence for larval sensory and navigational ability that may make directional movement possible. The agreement of the calculation shown above with those predicted elsewhere supports this hypothesis. An additional assumption of the diffusivity explanation is that it ignores the contribution of vertical migration in regulating spatial patterns. Vertical migration in areas of strong vertical shear such as estuaries may result in active retention or directed movements (Fortier \& Leggett 1982). However, the general weakening of flow magnitude with depth, and the presence of very little vertical shear in current flow in Placentia Bay (Schillinger et al. 2000) suggests that even if some vertical migration were occurring, resultant transport would still be consistent with mean horizontal flows, and vertical movement would contribute little to active retention within the bay.

\section{Patchiness}

Patchiness during the early life history of marine fishes may be adaptive and is considered an important life history trait (Hewitt 1981) that is potentially generated both by physical and biological processes. Utilization of specific spawning areas creates patches of early-stage eggs, which may then be dispersed or concentrated by physical processes. For cunner, American plaice, and Atlantic cod, patchiness indices generally increase during egg development. This increase suggests that mortality or physical processes may concentrate eggs in specific areas of the bay (in this case the western side, and to a lesser extent, the head).

Nonetheless, a stage-dependent mortality mechanism cannot be fully discounted. Bradbury et al. (2001) examined seasonal shifts in egg distribution and mortality. These authors observed changes in abundance or loss rates consistent with hydrography and temperature-dependent transport, and suggested that these processes dominate distribution patterns of pelagic eggs in Placentia Bay. Furthermore, an examination of size-dependent changes in the abundance of egg stages over time (authors' unpubl. data) revealed patterns consistent with those presented in Bradbury et al. (2001) and shows no evidence of stage- or sizedependent egg mortality. Thus, whereas a predation explanation cannot be fully discounted, it does necessitate invoking a stage-specific predation mechanism that is unlikely given the data. Moreover, previous work supports the more parsimonious explanation of movement.

If stage-specific predation is unlikely as a potential mechanism for generating increased patchiness in late- 
stage eggs, then eggs in this system could provide a crude, but natural, marker for passive dispersal. Assuming larvae are also passively dispersed, and in the absence of stage-specific larval mortality, it would be reasonable to predict that relative (rather than absolute) trends in patchiness of eggs and larvae would be similar. Contrary to the pattern observed for eggs, most larvae produced a U-shaped curve, with initially high patchiness in the smallest individuals, lower patchiness in medium-sized individuals and high patchiness in the largest individuals. Thus, active behaviour, or less likely predation, must be invoked as an explanatory mechanism.

Discounting egg predation does not eliminate the possibility that stage-specific larval mortality may contribute to larval patchiness curves and observed spatial patterns. For example, if mortality were most intense on mid- to early-stage larvae that are vulnerable because of small size or temporal abundance of predators, and assuming that larval patchiness was initially high because of spawning behaviour, then mortality may decrease patchiness (e.g. Fortier \& Leggett 1985). In theory, mortality could result from either starvation or predation. Pepin \& Penny (2000) examined consumption rates of microzooplankton by a larval fish community in coastal Newfoundland. They observed that $<0.1 \%$ of the available prey was consumed by the entire larval community and concluded that densitydependent growth or survival is unlikely to occur during this stage.

Furthermore, several sources of data address the alternate hypothesis of predation as the cause of selective mortality. Bradbury et al. (2000) examined changes in cod larvae distribution with size and found patterns in early larvae that were consistent with passive drift. There was, however, a suggestion of active movement or retention of older larvae near a second spawning area characterized by high production. Larval size increased with drift toward this area (Bradbury et al. 2000, their Fig. 10); however, mean larval size and variance decreased rapidly downstream of this spawning area. Active retention or movement appears a more likely mechanism for the observed spatial patterns. Finally there is some evidence in the data presented here (Fig. 3) that the increase in patchiness did not result from selective predation. Larval capelin (Fig. 3) undergo an ontogenetic shift in distribution to areas otherwise unoccupied. This pattern necessitates movement and is inconsistent with mortality as a factor. In summary, though we cannot completely refute the possibility that stage-dependent mortality contributes to our results, several lines of evidence suggest that active behaviour is more likely.

The role of behaviour in generating patchiness and spatial pattern in pelagic organisms is becoming in- creasingly accepted, even for relatively weak-swimming marine invertebrates (Folt \& Burns 1999). Initial observations of the changes in patchiness in pelagic eggs and larvae suggest contrasting processes of advection and diffusion away from spawning aggregations, and reaggregation with the development of schooling behaviour (Smith 1973, Hewitt 1981, Matsuura \& Hewitt 1995) or active aggregation around specific resources. If active behaviour does play a role, it could be in response to prey availability. Indeed, the increase in mean crowding of capelin larvae by potential prey species suggests that aggregation may, in part, be a result of active accumulation in areas with increased prey availability.

Laboratory observations of behaviour in pelagic larvae such as capelin (Morgan et al. 1995) suggest that schooling behaviour is present from hatch, and that the time spent schooling increases rapidly during development. In such a situation, increases in patchiness through time would be consistent with a transition when swim speeds exceed ambient flows and aggregative behaviour is manifested in the form of increased patchiness. In the scaling model outlined in Fig. 8, the intercept of swim speeds with current speeds approximates the point where patchiness begins to increase during the larval period, supporting the assertion that changes in patchiness may be related to an increasing role for active behaviour.

Previous authors have addressed the role of behaviour in changing patterns of patchiness. Frank et al. (1993) estimated changes in patchiness for capelin larvae in coastal Newfoundland. They observed a U-shaped patchiness at size curve (sensu Fig. 6), in which the trough of the curve coincided with patchiness estimates for a similar-sized non-schooling invertebrate. They concluded that changes in patchiness with development were a product of both capelin behaviour, which creates high levels of patchiness at initial hatch, and larval behaviour, which caused patchiness at later developmental stages. Similarly, in a study of changes in patchiness during development in walleye pollock, Stabeno et al. (1996) utilized simulation experiments to conclude that after ca. 5 to $6 \mathrm{wk}$, larvae have the swimming ability required to maintain patches that are initially generated by physical mechanisms. Interestingly, the size at which this transition occurs was estimated to be $\sim 11$ to $15 \mathrm{~mm}$. This coincides with our estimates of the critical transition size for larval fish in Placentia Bay. Fortier \& Leggett (1982) suggested that herring larvae smaller than $10 \mathrm{~mm}$ were unable to undergo vertical migrations, yet larvae larger than $10 \mathrm{~mm}$ performed extensive migrations which significantly impacted their horizontal dispersal. The concordance in findings in these different studies is not surprising given that swimming ability is a func- 
tion of length and beat frequency, and is likely to be relatively uniform across temperate species at comparable developmental stages (Williams et al. 1996).

Our findings are consistent with, and add to, the accumulating evidence that marine population structure is smaller in scale and more localized than had previously been believed (e.g. Thorrold et al. 2001). Admittedly, localized hydrography may play a role; however, the temporal stability of hydrographic features is often insufficient to maintain larvae until settlement (Bradbury \& Snelgrove 2001). We conclude that active contributions may be significant over larger spatial scales and may contribute to spatial pattern and, therefore, marine fish population structure.

Acknowledgements. The authors would like to thank all members of the Fisheries Conservation Chair, and the crews of the RV 'Mares' and CV 'Shamook'. D. Methven, D. Schneider, R. Hewitt, L. Barrett and B. Laurel assisted and advised on data analysis and interpretation. T. Shears offered advice on data collection, S. Fraser, T. Brown, and J. Martin assisted with sample collection and analysis. W. Leggett, D. Methven, and 2 anonymous reviewers provided very helpful comments on earlier drafts of this manuscript. The advice and expertise of the Atlantic Reference Center in sorting and identification is also much appreciated. This research was supported by the NSERC Industrial Chair in Fisheries Conservation at Memorial University of Newfoundland.

\section{LITERATURE CITED}

Bez N (2000) On the use of Lloyd's index of patchiness. Fish Oceanogr 9:372-376

Bliss CI, Fisher RA (1953) Fitting the negative binomial distribution to biological data. Biometrics 9:176-200

Bradbury IR, Snelgrove PVR (2001) Contrasting larval transport in demersal fish and benthic invertebrates: the roles of behaviour and advective processes in determining spatial pattern. Can J Fish Aquat Sci 58:811-823

Bradbury IR, Snelgrove PVR, Fraser S (2000) Transport and development of eggs and larvae of Atlantic cod, Gadus morhua, in relation to spawning time and location in coastal Newfoundland. Can J Fish Aquat Sci 57:1761-1772

Bradbury IR, Snelgrove PVR, Fraser S (2001) The influence of temperature on the loss of Atlantic cod (Gadus morhua) eggs and larvae from the inshore environment: a combined modelling and observational approach. Fish Oceanogr 10:342-352

Butman CA, Grassle JP, Webb CM (1988) Substrate choices made by marine larvae settling in still water and in a flume flow. Nature 333:771-773

Chambers RC (1997) Environmental influences on egg and propagule sizes in marine fishes. In: Chambers RC, Trippel EA (eds) Early life history and recruitment in fish populations. Chapman \& Hall, New York

Cowen RK, Lwiza KMM, Sponaugle S, Paris CB, Olson DB (2000) Connectivity of marine populations: open or closed? Science 287:857-859

deYoung B, Sanderson BR (1995) The circulation and hydrography of Conception Bay. Atmos Ocean 33:135-162

Folt CL, Burns CW (1999) Biological drivers of zooplankton patchiness. Trends Ecol Evol 14:300-305
Fortier L, Leggett WC (1982) Fickian transport and the dispersal of fish larvae in estuaries. Can J Fish Aquat Sci 39: 1150-1163

Fortier L, Leggett WC (1985) A drift study of larval fish survival. Mar Ecol Prog Ser 25:245-257

Frank KT, Carscadden JE, Leggett WC (1993) Causes of spatio-temporal variation in the patchiness of larval fish distributions: differential mortality or behaviour? Fish Oceanogr 2:114-122

Gaines SD, Bertness MD (1992) Dispersal of juveniles and variable recruitment in sessile marine species. Nature 360: 570-583

Grioche A, Harlay X, Koubbi P, Lago LF (1999) Vertical migrations of fish larvae: Eulerian and Lagrangian observations in the eastern English Channel. J Plankton Res 22: $1813-1828$

Hare JA, Fahay MP, Cowen RK (2001) Springtime ichthyoplankton of the slope region off the north-eastern United States of America: larval assemblages, relation to hydrography and implications for larval transport. Fish Oceanogr 10:164-192

Hewitt R (1981) The value of pattern in the distribution of young fish. Rapp P-V Reun Cons Int Explor Mer 178: $228-236$

Jones GP, Milicich MJ, Emslie MJ, Lunow C (1999) Selfrecruitment in a coral reef fish population. Nature 402: 802-804

Kingsford MJ, Leis JM, Shanks A, Lindeman KC, Morgan SG, Pineda J (2002) Sensory environments, larval abilities and local self-recruitment. Bull Mar Sci 70:309-340

Leis JM, Carson-Ewart BM (1999) In situ swimming and settlement behaviour of larvae of an Indo-Pacific coralreef fish, the coral trout Plectropomus leopardus (Pisces: Serranidae). Mar Biol 134:51-64

Lloyd M (1967) Mean crowding. J Anim Ecol 36:1-30

MacCall AD (1990) Dynamic geography of marine fish populations. Washington Sea Grant, Seattle

Markle DF, Frost LA (1985) Comparative morphology, seasonality, and a key to planktonic fish eggs from the Nova Scotia Shelf. Can J Zool 63:246-257

Matsuura Y, Hewitt R (1995) Changes in the spatial patchiness of Pacific mackerel, Scomber japonicus, larvae with increasing age and size. Fish Bull 93:172-178

McGurk MD (1986) Natural mortality of marine pelagic fish eggs and larvae: role of spatial patchiness. Mar Ecol Prog Ser 34:227-242

Methven DA, Schneider DC, Rose GA (2003) Spatial pattern and patchiness during ontogeny: post-settled Gadus morhua from coastal Newfoundland. ICES J Mar Sci 60:38-51

Mora C, Sale P (2002) Are populations of coral reef fish open or closed? Trends Ecol Evol 17:422-428

Morgan MJ, Anderson JT, Brown JA (1995) Early development of shoaling behavior in larval capelin (Mallotus villosus). Mar Behav Physiol 24:197-206

O'Driscoll RL, Schneider DC, Rose GA, Lilly GR (2000) Potential contact statistics for measuring scale-dependent spatial pattern and association: an example of northern cod (Gadus morhua) and capelin (Mallotus villosus). Can J Fish Aquat Sci 57:1355-1368

Pepin P (1991) Effect of temperature and size on development, mortality, and survival rates of the early life history stages of marine fish. Can J Fish Aquat Sci 48:503-518

Pepin P, Penny R (2000) Feeding by a larval fish community: impact on zooplankton. Mar Ecol Prog Ser 204:199-212

Pepin P, Helbig JA, Laprise R, Colbourne E, Shears TH (1995) Variations in the contribution of transport to changes in planktonic animal abundance: a study of the flux of fish 
larvae in Conception Bay, Newfoundland. Can J Fish Aquat Sci 52:1475-1486

Roughgarden J, Gaines SD, Possingham H (1988) Recruitment dynamics in complex life cycles. Science 241:1460-1466

Schillinger DJ, Simmons P, deYoung B (2000) Analysis of the mean circulation in Placentia Bay during spring and summer 1999. Physics and physical oceanography data report 2000-1. Dept of Physics and Physical Oceanography, Memorial University of Newfoundland, St. John's

Sinclair M (1988) Marine populations: an essay on population regulation and speciation. Washington Sea Grant, Seattle

Smith PE (1973) The mortality and dispersal of sardine eggs and larvae. Rapp P-V Reun Cons Int Explor Mer 164: 282-292

Sokal RR, Rohlf FJ (1995) Biometry: the principles and practice of statistics in biological research. WH Freeman, New York

Stabeno PJ, Schumacher JD, Bailey KM, Brodeur RD, Cokelet ED (1996) Observed patches of walleye pollock eggs and larvae in Shelikof Strait, Alaska: their characteristics, formation and persistence. Fish Oceanogr 5:81-91

Suthers I, Frank KT (1991) Comparative persistence of marine fish larvae from pelagic versus demersal eggs off southwestern Nova Scotia, Canada. Mar Biol 108:175-184

Editorial responsibility: Kenneth Sherman (Contributing Editor), Narragansett, Rhode Island, USA
Swearer SE, Caselle JE, Lea DW, Warner RR (1999) Larval retention and recruitment in an island population of a coral reef fish. Nature 402:799-802

Thorrold SR, Latkoczy C, Swart PK, Jones CM (2001) Natal homing in a marine fish metapopulation. Science 291: 297-299

Thresher RE (1984) Reproduction in reef fishes. TFH Publications, Neptune City, NJ

Warner RR, Swearer SE, Caselle JE (2000) Larval accumulation and retention: implications for the design of marine reserves and essential fish habitat. Bull Mar Sci 66: 821-830

Werner FE, Blanton BO, Quinlan JA, Luettich RA Jr (1999) Physical oceanography of the North Carolina continental shelf during the fall and winter seasons: implications for the transport of larval menhaden. Fish Oceanogr 8: $7-21$

Williams PJ, Brown JA, Gotceitas V, Pepin P (1996) Developmental changes in escape response performance of five species of marine larval fish. Can J Fish Aquat Sci 53: 1246-1253

Zhao Y, Chen Y, Brown JA (2001) Impacts of egg and larval size on survival and growth of Atlantic cod under different feeding conditions. J Fish Biol 59:569-581

Submitted: July 27, 2002; Accepted: March 17, 2003

Proofs received from author(s): July 23, 2003 